\title{
NOTE SUR L'INTÉGRATION DE LA PISCICULTURE DANS LES ACTIVITÉS AGRICOLES: L'EXEMPLE DE LA CHINE
}

\author{
Gérard BALVAY \\ Station d'Hydrobiologie Lacustre, I.N.R.A. \\ 74203 THONON
}

\begin{abstract}
Hormis le cas des étangs de production où l'homme arrive dans une certaine mesure à contrôler l'écosystème et la production qui en découle, les milieux aquatiques ne sont que rarement l'objet d'une véritable gestion agronomique. En Côte d'lvoire, des élevages de porcs ont eté associès à une pisciculture de Tilapia nilotica, les sous-produits de l'élevage (fumier, restes d'aliments) allant dans l'étang et servant à la fois d'engrais pour le milieu aquatique et d'aliment pour les poissons (MORISSENS, 1979). II existe cependant des cas où l'étang peut être véritablement intégré à l'agrosysteme : en Chine, l'aquaculture d'eau douce fait partie intégrante du système global de production agricole à l'échelle nationale (TAPIADOR et al., 1977 ; LEONARD, 1977)
\end{abstract}

Cette intégration permet l'utilisation complète des résidus agricoles de la ferme. Les cultures produisent la nourriture pour les animaux, les poissons et l'homme. Les animaux (volailles, bovins, ovins) assurent la fertilisation organique des champs et des étangs; un élevage de 30 à 45 porcs fournit assez d'engrais pour un hectare de plan d'eau. La vase qui s'accumule dans les étangs est périodiquement enlevée et redistribuée comme engrais sur les cultures; ce dévasement régulier améliore les conditions d'oxygénation des étangs par élimination de la matière organique sédimentée. Les diverses espèces de poissons élevées en polyculture permettent d'utiliser au mieux la production naturelle du réseau trophique de l'étang, stimulée ou complétée par les apports constants en provenance du milieu extérieur.

Selon les renseignements recueillis en Chine par TAPIADOR et al. (1977), $100 \mathrm{~m}^{2}$ d'herbes fournissent assez de nourriture pour 0,1 ha d'étang et $60 \mathrm{~kg}$ de fourrage assurent la production de $1 \mathrm{~kg}$ de * carpe herbivore = " carpe des roseaux - (Ctenopharyngodon idella); $50 \mathrm{~kg}$ de fumure organique produite par les animaux de la ferme permettent d'obtenir $1 \mathrm{~kg}$ de * carpe argentée (Hypophthalmichthys molitrix) ou de "carpe marbrée. $=$ * carpe à grosse tête. (Aristichthys nobilis). 
L'apport de $100 \mathrm{~kg}$ d'eaux fertiles enrichies en épluchures de soja et en résidus fermentés (respectivement $77 \%$ et $23 \%$ ) entraine la production de $1 \mathrm{~kg}$ de carpe argentée et $50 \mathrm{~kg}$ de mollusques (pouvant être récoltés en abondance dans d'autres plans d'eau) permettent d'obtenir $1 \mathrm{~kg}$ de * carpe noire - (Mylopharyngodon piceus).

Les excrements des poissons fertilisent le milieu et entrainent une augmentation de la production de la biocenose planctonique, utilisable par les poissons : $1 \mathrm{~kg}$ de ces excrements permet alors la production supplémentaire de $1,6 \mathrm{~kg}$ de carpe argentée ou marbrée. En polyculture, $7.5 \mathrm{~kg}$ de ces diverses carpes enrichissent suffisamment la vase pour que celle-ci assure à son tour la fertilisation de $1000 \mathrm{~m}^{2}$ de cultures.

Cet écosystème fonctionne en l'absence d'aliments industriels et de produits chimiques fertilisants. La seule fertilisation est de nature organique. fournie directement par les animaux et indirectement par les résidus vegetaux et la nourriture naturelle distribuée aux poissons.

Grâce aux conditions politiques, économiques et socio! ogiques qui existent en Chine l'integration de la pisciculture d'eau douce dans l'agrosystème peut être considérée comme une réussite.

\section{BIBLIOGRAPHIE}

LEONARD S., 1977. - L'aquaculture chinoise. La Pisciculture Française, 52 : 39-43.

MORISSENS P., 1979. - Un premier test d'élevage de porcs associè à la pisciculture de Tilapia nilotica à la station de Bouaké (Côte d'lvoire). Notes Doc. Pêche Piscic. Cent. Tech. Forest. Tropic., $19: 27-50$.

TAPIADOR D.D., HENDERSON H.F., DELMENDO M.N. et TSUTSUI H., 1977. - Fresh. water fisheries and aquaculture in China. F.A.O. Fish. Tech. Pap. 168:1-84.

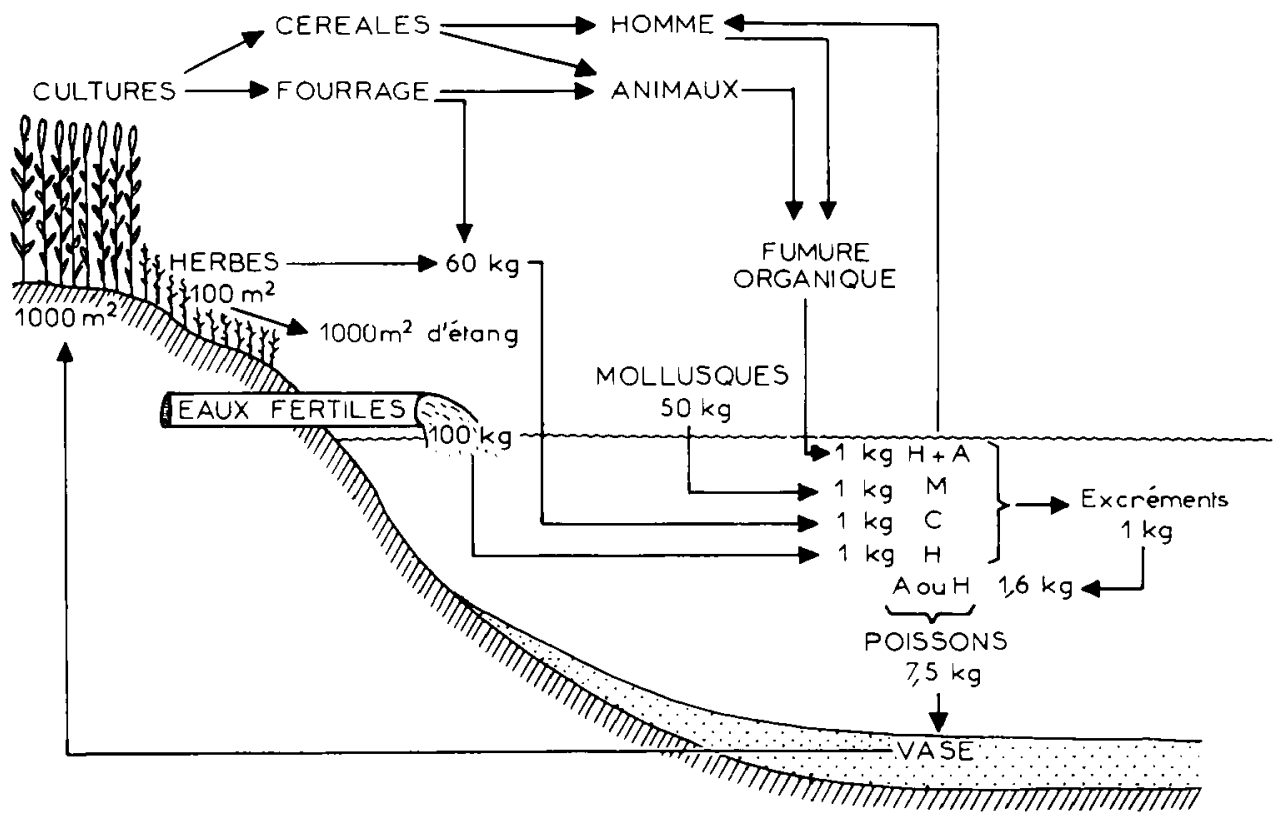

Figure : Principe de fonctionnement d'un étang de pisciculture intégrè à un agrosystème (d'après les données chiffrées recueillies par TAPIADOR et al. 1977).

A : Aristichthys nobilis : carpe marbrée ou carpe à grosse tête.

C : Ctenopharyngodon idella : carpe herbivore = carpe des roseaux.

H : Hypophthalmichthys molitrix : carpe argentée.

M : Mylopharyngodon piceus : carpe noire. 